\title{
Health-Related Quality of Life (HRQoL) scores vary with treatment and may identify potential defaulters during treatment of tuberculosis
}

Adewole Olanisun Olufemi ${ }^{1}$, Ayuk Adaeze Chikaodinaka ${ }^{2}$, Philips Abimbola ${ }^{3}$, Adewole Temitayo Oluwatoyin ${ }^{4}$, Alabi Oluwafunmilola ${ }^{1}$, Kolawole Tope Fasanmi ${ }^{1}$, Erhabor Gregory Efosa ${ }^{1}$

1. Department of Medicine, Obafemi Awolowo University Teaching Hospital Ile Ife, Nigeria

2. Department of Paediatrics University of Nigeria Teaching Hospital, Enugu Nigeria

3. Department of Community Health, Obafemi Awolowo University Teaching Hospitals, Ile Ife, Nigeria

4. Department of Family Medicine, Obafemi Awolowo University Teaching Hospital Ile Ife, Nigeria

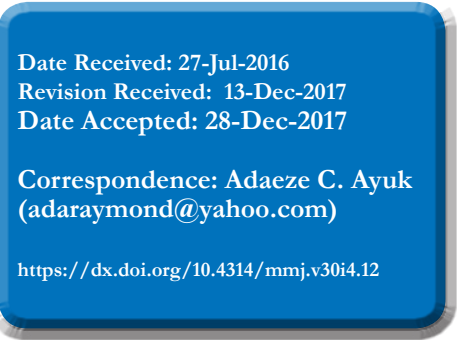

Introduction

\section{Abstract}

Nigeria ranks third among the 22 high-burden TB countries in the world. With the availability of effective treatment strategies, and more patients surviving the disease, assessment of Patient Reported Outcomes (PROs) has become imperative to assist with patient evaluation of measured outcomes and thus improve morbidity. Literature is scarce on assessment and impact of chemotherapy on Health-Related Quality of Life (HRQoL) for patients with tuberculosis.

Aim

This study evaluates the variation in Health-Related Quality of Life (HRQoL) in pulmonary TB patients during the intensive phase of treatment.

Methods

We recruited patients with pulmonary TB (PTB), from 3 different TB clinics across Ife Ijesha Zone, Osun State, Nigeria. Consenting patients were administered Short Form-36 HRQoL questionnaire at recruitment and at the end of intensive phase of treatment. HRQoL scores were compared at these two-time points, the degrees of changes were calculated and relationships with some. Directly Observed Therapy-Short (DOTS) course outcome measures were obtained. Logistic regression was used to identify factors associated with greatest change in HRQoL scores.

Results

Of the 130 recruited patients, we analysed data for 126 patients who met the inclusion criteria. Mean age was 36.7(SD15.5). The overall mean HRQoL score obtained at enrolment was 43.18 (SD 17.2) and 60.22 (SD19.83) at end of 2 months; mean change $=17.04$ $\mathrm{p}<0.001)$. The least change was on the emotional well-being domain (mean change $=4.24, \mathrm{p}=0.05$ ). Predictor of significant change in HRQoL scores were previous history of TB, HIV status and TB severity, $\mathrm{p}<0.05$ each. High physical functioning score was a strong predictor of defaulters $(\mathrm{OR}=5.3$; 95\%CI: 2.11-9.05, $\mathrm{p}=0.01)$.

Conclusion

Emotional domain is least affected by PTB while younger patients with no physical impairment are more likely to default treatment. Various aspects of HRQoL can be a useful tool for patient's evaluation and outcome prediction.

Key Words: HRQoL, DOTS, defaulters, TB, treatment, physical function

\section{Introduction}

Quality of life (QoL) is a broad, multidimensional concept incorporating in a complex way, the person's physical health, psychological state, level of independence, social relationships, personal beliefs and their relationship to salient features of the environment $t^{1,2}$. It describes the satisfaction felt by an individual with the various aspects of his or her life $^{1,2}$. TB has remained a major public health threat globally with the developing countries bearing the greatest brunt ${ }^{3}$. Nigeria ranks third among the 22 high-burden TB countries in the world, and first in Africa ahead of South Africa ${ }^{3}$. With the development and availability of effective treatment strategies for TB and with more patients surviving the disease and living longer, a shift in the traditional evaluation of patients based on clinical and microbiological outcome is imperative. TB affects the Health-Related Quality of Life (HRQOL) both before and during treatment ${ }^{4-10}$. If the gains of the current TB control efforts are to be sustained, it is important that TB management should embrace measures to improve morbidity outcomes. The assessment of Patient Reported Outcomes (PROs) has become more accepted and valued in the disease management and outcome evaluation ${ }^{1,6}$. Despite the huge number of TB patients in Nigeria, literature is scarce on information on the quality of life for patients with tuberculosis and especially the impact of chemotherapy on patients' HRQoL. This is quite important as patients' perception of their disease and the improvement brought by anti TB drugs will assist in ensuring compliance with treatment and thereby prevent emergence of resistance strains. This study investigates the HRQoL among treatment-naive TB patients to determine the predictors of improvement in their quality of life and how it varies with treatment outcome by the end of intensive phase of treatment.

\section{Methods}

\section{Study Design and Population}

This was a cross sectional study conducted among treatmentnaive TB patients in three Directly Observed Therapy (DOT) clinics within 2 to $16 \mathrm{~km}$ from each other in Ile 
Ife, Osun State, Nigeria (the TB Clinic, Obafemi Awolowo University Teaching Hospitals Complex (OAUTHC), Ile Ife, Enuwa TB clinic and Moro TB clinic). Ethical Clearance was obtained from the OAUTHC Ethics and Research Committee (ERC/2012/11/06 No, and Ministry of Health, Osun State, while informed Consent was obtained from each participant/Legally Accepted Representative (LAR), before commencement of the study. The study design is as illustrated in S1 in line with Strengthening the Reporting of Observational studies in Epidemiology (STROBE) guideline $^{12}$.

Consenting patients with pulmonary tuberculosis diagnosed according to the Nigerian National Tuberculosis and Leprosy Control Program Guidelines, and who met the inclusion criteria were consecutively recruited at each of the study clinics ${ }^{11}$. The inclusion criteria included: Participants aged 15 and above who gave consent/assent to participate in the study; who were not already started on anti-TB treatment; and were resident in study locality. Patients less than 15 years or whose LAR refused consent, those already on TB treatment, those with co-existing medical conditions like renal failure, liver disease, and pregnancy or anyone who had difficulties in understanding the questionnaire were excluded from the study. Both smear positive and smear negative PTB patients, new and retreatment cases and those with HIV positive result who met the inclusion criteria were recruited.

\section{Measurements and Data Collection}

Trained research assistants interviewed the enrolled participants to obtain the requisite data including age at last birthday, sex, Body Mass Index, place of domicile, history of tobacco use, HIV status and duration of TB symptoms before presenting to the health facility. To ascertain the socioeconomic status of the individual, the method that rated the occupation and educational qualification was used ${ }^{12}$.

The HRQoL was assessed using the intervieweradministered Short-Form 36(SF-36) questionnaire. The SF-36 questionnaire is a generic instrument designed to assess in a broad sense, the impact of disease on health It has been used extensively in most assessment of TB patients ${ }^{5-7,13-15}$. The validated and pre-tested English version and a validated back-translated previously piloted Yoruba version (concurrent validity scores for scales and domains 0.749 and 0.902), of the questionnaires were used ${ }^{16}$. The SF-36 questionnaire contains 36 questions grouped into 8 subscales, covering multiple aspects of health, including physical function, social function, general health, vitality and limitations due to physical, emotional functioning, roleemotional and mental health ${ }^{12-15}$. From the eight subscales, the physical component summary (PCS), mental component summary (MCS) and overall scores can be calculated. For each subject, the original response (scored between 0 to 5 ) on each question is recoded on a scale of 0 to 100 , with 100 representing the highest level of functioning possible ${ }^{15}$. From these recoded values, the items scores were averaged and combined to form the 8 subscales. Aggregate scores were compiled as a percentage of the total points possible ${ }^{15}$. Scores from the 8 subscales were also aggregated to generate the Physical Health Component Score and the Mental Health Component Score.

To assess severity of $\mathrm{TB}$, a validated $\mathrm{TB}$ score system, Bandim TB score (BTB) consisting of 13 items of signs and symptoms, was used ${ }^{17}$. The signs and symptoms used in this scoring system include cough, haemoptysis, fever, chest pain, positive finding on auscultations, the body mass index (BMI), mid upper arm circumference and others. Each item is scored one mark if present, and the sum of all the scores was used to classify severity as follows: Severity Class(SC), SC-I for TB score of 0-5; SC-II for TB score of 6-7; and SC-III for score of 8 points and above. The patients were subsequently commenced on anti $\mathrm{TB}$ drugs in accordance with the National TB Control Guideline in Nigeria ${ }^{11}$. The quality of life (total and domain) assessments were evaluated at start of treatment and after two months of treatment (end of intensive phase).

\section{Statistics}

Information obtained from the participants was analysed using Statistical Package for Social Sciences (SPSS) software version 19 for Windows ${ }^{\circledR}$. Frequencies of the various numerical variables such as age, duration of symptoms were analysed using mean, median and standard deviations. Variables with normal distribution were analysed with parametric statistical tools while those that are of nonnormal distribution were analysed with non-parametric tools like Mann Whitney U test. To determine the level of significance for the variables, Chi-square statistics or Fisher exact test was used for multiple categorical variables. To interpret possible significance of the outcomes amongst group variables during treatment, Norm Based Score (NBS) $\geq 3$-point change in the health domain scales and component summary measures represented minimal clinically important difference (MCID) $)^{15}$. Hence, individuals with higher point change implied higher degree of improvement. A score on a health domain scale or component summary measure that was less than $47 \mathrm{NBS}$ point was considered indicative of impaired function within that health domain or dimension ${ }^{15}$. Logistic regression analysis was used to determine the independent variables that were predictive of the greatest improvement in the quality of life scores after the intensive phase of treatment compared to baseline, using the backward elimination method. Mann Whitney U test was used to test for relationship between HRQoL scores among defaulters and non-defaulters at the end of intensive phase. Level of significance was put at $\mathrm{p}<0.05$ for all the statistical analyses, with a minimum power of $80 \%$ for the confidence interval of $95 \%$.

\section{Results}

\section{Characteristics of the study population}

Of the 130 PTB patients recruited, four had incomplete data and were excluded from further analysis, (SI appendix). Analyses were done for the remaining 126 participants. The mean age of study participants was 36.7(SD15.5) years with $95(74 \%)$ of them between the ages of 20 and 49 years old. (Table 1) There were slightly more males 68(53.5\%) than females. Most of the participants 118(94\%) had a BMI of less than 24.9. Table 1 further highlights the socio-demographic and clinical characteristics of the study participants. Of the total studied, $13(10 \%)$ had a history of tobacco use, $8(6 \%)$ were HIV positive while $26(20 \%)$ had been previously treated for TB. History of symptoms consistent with PTB had been present for 1 to 6 months in 79(61\%) of the study participants. Majority 103(82\%) were in severity class I. Overall, 115(91.5\%) were smear positive while $11(8.5 \%)$ had smear negative TB. 
Table 1: Socio-demographic characteristics of study participants

\begin{tabular}{|c|c|c|c|c|}
\hline Variables & $\begin{array}{c}\text { TOTAL } \\
\mathrm{n}(\%)\end{array}$ & $\begin{array}{c}\text { MALE } \\
\mathrm{n}(\%)\end{array}$ & $\begin{array}{c}\text { FEMALE } \\
\mathrm{n}(\%)\end{array}$ & $p$ values \\
\hline Age (years) & $126(100)$ & $67(53.5)$ & $59(46.5)$ & 0.371 \\
\hline $15-20$ & $10(7.9)$ & $3(4.5)$ & $7(11.9)$ & \\
\hline 20 to 29 & $39(31.0)$ & $21(31.3)$ & $18(30.5)$ & \\
\hline 30 to 39 & $30(23.8)$ & $14(20.9)$ & $16(27.1)$ & \\
\hline 40 to 49 & $26(20.6)$ & $17(25.4)$ & $9(15.3)$ & \\
\hline 50 to 59 & $9(7.1)$ & $4(6.0)$ & $5(8.5)$ & \\
\hline 60 and above & $12(9.5)$ & $8(11.9)$ & $4(6.8)$ & \\
\hline BMI & & & & 0.342 \\
\hline$<18.5$ & $53(42.1)$ & $29(42.6)$ & $24(42.1)$ & \\
\hline 18.5 to 24.9 & $65(51.6)$ & $37(54.4)$ & $27(47.4)$ & \\
\hline 25.0 to $<29.9$ & $5(4.0)$ & $1(1.5)$ & $4(7.0)$ & \\
\hline$\geq 30.0$ & $3(2.4)$ & $1(1.5)$ & $2(3.5)$ & \\
\hline$<18.5$ & $53(42.1)$ & $29(42.6)$ & $24(42.1)$ & \\
\hline \multicolumn{5}{|l|}{$\begin{array}{l}\text { Health } \\
\text { variables: }\end{array}$} \\
\hline TB & & & & 0.685 \\
\hline New TB patient & $100(79.4)$ & $54(80.5)$ & $46(78.0)$ & \\
\hline $\begin{array}{l}\text { Retreatment } \\
\text { TB patient }\end{array}$ & $26(20.6)$ & 13 & $(19.5)$ & \\
\hline HIV status & & & & 0.471 \\
\hline HIV positive & $8(6.3)$ & 3 & $(4.5)$ & \\
\hline HIV negative & 118(93.7) & 64 & $(95.5)$ & \\
\hline $\begin{array}{l}\text { Tobacco } \\
\text { exposure }\end{array}$ & & & & 0.020 \\
\hline Tobacco use & $13(10.3)$ & $11(16.4)$ & $2(3.4)$ & \\
\hline $\begin{array}{l}\text { No Tobacco } \\
\text { use }\end{array}$ & $113(89.1)$ & $56(83.6)$ & $57(96.6)$ & \\
\hline $\begin{array}{l}\text { Duration of } \\
\text { TB symptoms } \\
\text { (months) }\end{array}$ & & & & 0.781 \\
\hline 0 to $<1$ & $32(25.4)$ & $17(25.0)$ & $15(25.4)$ & \\
\hline 1 to 6 & $77(61.1)$ & $40(58.8)$ & 37 (62.7) & \\
\hline$>6$ & $17(13.5)$ & $10(14.9)$ & $7(11.9)$ & \\
\hline $\begin{array}{l}\text { TB severity } \\
\text { class }\end{array}$ & & & & 0.08 \\
\hline I & $103(82.0)$ & $55(82.1)$ & $48(81.4)$ & \\
\hline$\|$ & $14(11.0)$ & $6(8.9)$ & $8(13.6)$ & \\
\hline III & $9(6.9)$ & $6(8.9)$ & $3(5.0)$ & \\
\hline
\end{tabular}

\section{Quality of life scores among TB patients}

The overall mean quality of life score obtained in all study participants at enrolment was 43.18 (SD 17.2). By the end of the intensive phase $17(13.49 \%)$ patients had defaulted (11 smear positive and 6 smear-negative). For the remaining $109(86.51 \%)$, the overall mean quality of life score at the end of intensive phase was 60.22 (SD19.83); mean change $(\mathrm{MCID})=17.04 \mathrm{p}<0.001)$, Table 2 .

Before therapy was commenced, patients had highest HRQoL score on the Pain domain, 56.65 (SD16.60) and lowest in the Role limitation domain, 17.44 (SD33.74). At the end of intensive phase, patients had the largest increase in the Role limitation domain (MCID 36.8, $\mathrm{p}<0.001$ ) and the least and insignificant change on the emotional well-being domain $(\mathrm{MCID}=4.24, \mathrm{p}=0.05)$. There were significant changes in the other domains as shown in Table 2.

Table 2: HRQoL scores at recruitment and at the end of intensive phase

\begin{tabular}{|c|c|c|c|c|}
\hline Domains & $\begin{array}{l}\text { Mean Score (SD) } \\
\text { at } 0 \text { month }\end{array}$ & $\begin{array}{l}\text { Mean Score (SD) } \\
\text { at } 2 \text { months }\end{array}$ & $\begin{array}{l}\text { Mean } \\
\text { change } \\
\text { (MCID) }\end{array}$ & $P$ values \\
\hline Physical function & $50.47(23.44)$ & $61.32(29.87)$ & 10.84 & $<0.001$ \\
\hline $\begin{array}{l}\text { Role limitation } \\
\text { (Physical) }\end{array}$ & 17.4433.74) & $54.26(44.65)$ & 36.82 & $<0.001$ \\
\hline $\begin{array}{l}\text { Role limitation } \\
\text { (emotional) }\end{array}$ & $19.75(34.26)$ & $54.06(44.02)$ & 34.30 & $<0.001$ \\
\hline Energy fatigue & $50.08(21.61)$ & $60.08(19.16)$ & 10.00 & $<0.001$ \\
\hline $\begin{array}{l}\text { Emotional } \\
\text { wellbeing }\end{array}$ & $55.45(16.60)$ & $59.69(18.57)$ & 4.24 & 0.05 \\
\hline Social function & $49.32(22.28)$ & $61.34(20.34)$ & 12.02 & $<0.001$ \\
\hline Pain & $56.65(26.48)$ & $69.61(22.67)$ & 12.97 & $<0.001$ \\
\hline General health & $43.80(18.87)$ & $60.47(19.27)$ & 16.67 & $<0.001$ \\
\hline $\begin{array}{l}\text { Physical } \\
\text { Component }\end{array}$ & $42.09(19.97)$ & $61.41(24.28)$ & 19.32 & $<0.001$ \\
\hline $\begin{array}{l}\text { Mental } \\
\text { Component }\end{array}$ & $43.65(18.09)$ & $58.79(19.86)$ & 15.14 & $<0.001$ \\
\hline Overall HRQoL & $43.18(17.20)$ & $60.22(19.83)$ & 17.04 & $<0.001$ \\
\hline
\end{tabular}

Although the baseline total HRQoL scores between the defaulters and those that completed the intensive phase of treatment were similar: median (IR) 46.7(SD 17.2) and $43.7(\mathrm{SD}$ 17.1) respectively, $\mathrm{p}=0.06$, defaulters had significantly higher score on physical functioning at 0 month compared with those who did not default, (62.3 (SD 20.1) and 49.4 (SD23.6) respectively, $\mathrm{p}=0.03)$, (Figure 1).

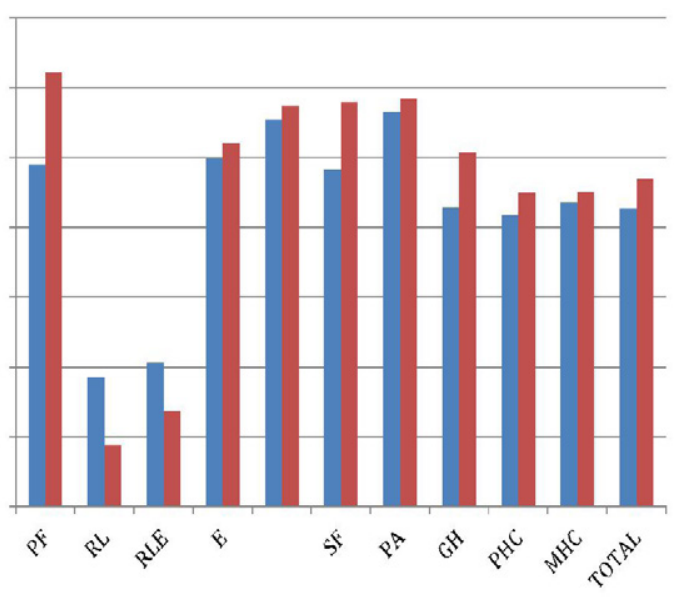

Figure 1: HRQoL scores for defaulters and non- defaulters at the end of intensive phase

\section{non defaulters $\square$ Defaulters}

${ }^{*}$ PF: Physical functioning, RL: Role Limitation, RLE: Role limitation emotional, E:Energy,EWB: Emotional

wellbeing, SF: Social functioning, PA: Pain, GH: General Health, PHC: Physical Component Summary, MHC: Mental Component Summary* $\mathrm{p}$ value less than $\mathbf{0 . 0 5}$, Mann Whitney $\mathrm{U}$ test was used.

HRQoL scores were also compared among 91.8\% (90/98) who were smear converted, and $8.2 \%(8 / 98)$ that remained smear positive at the end of intensive phase. There were no significant differences in the Physical and Mental 
Components summary scores and overall scores between the two groups.

Table 3: Factors associated with mean change in QOL Scores at completion of intensive phase treatment

\begin{tabular}{|c|c|c|c|}
\hline Domains & $\begin{array}{l}\text { Physical Health } \\
\text { Change score }\end{array}$ & $\begin{array}{l}\text { Mental Health } \\
\text { Change } \\
\text { score }\end{array}$ & $\begin{array}{l}\text { Overall QOL } \\
\text { Change score }\end{array}$ \\
\hline \multicolumn{4}{|l|}{ Age (years) } \\
\hline $15-20$ & 18.98 & 16.91 & 20.60 \\
\hline $20-29$ & 19.71 & 18.05 & 18.35 \\
\hline $30-39$ & 23.17 & 18.25 & 21.75 \\
\hline $40-49$ & 14.88 & 11.36 & 12.08 \\
\hline $50-59$ & 0.42 & -3.74 & -3.88 \\
\hline$\geq 60$ & 30.91 & 18.12 & 23.78 \\
\hline$p$-value & 0.28 & 0.34 & 0.15 \\
\hline \multicolumn{4}{|l|}{ Sex } \\
\hline Male & 20.59 & 15.98 & 18.22 \\
\hline Female & 18.30 & 14.09 & 16.00 \\
\hline$p$-value & 0.67 & 0.70 & 0.65 \\
\hline \multicolumn{4}{|l|}{ Previous TB } \\
\hline $\begin{array}{l}\text { New TB } \\
\text { patient }\end{array}$ & 35.21 & 30.07 & 32.34 \\
\hline $\begin{array}{l}\text { Retreatment } \\
\text { TB patient }\end{array}$ & 15.32 & 11.37 & 13.18 \\
\hline$p$-value & $<0.001$ & $<0.001$ & $<0.001$ \\
\hline \multicolumn{4}{|l|}{$\begin{array}{l}\text { Duration of } \\
\text { TB symptoms } \\
\text { (months) }\end{array}$} \\
\hline 0 to $\leq 1$ & 30.56 & 26.18 & 26.66 \\
\hline$>1$ to 6 & 13.91 & 11.72 & 12.62 \\
\hline$>6$ & 23.13 & 10.50 & 17.60 \\
\hline$p$ value & 0.03 & 0.03 & 0.03 \\
\hline \multicolumn{4}{|l|}{ BMI } \\
\hline Underweight & 25.17 & 20.25 & 23.13 \\
\hline Normal & 15.83 & 11.78 & 12.92 \\
\hline $\begin{array}{l}\text { Overweight/ } \\
\text { Obese }\end{array}$ & 8.98 & 5.32 & 9.14 \\
\hline$p$-value & 0.14 & 0.14 & 0.08 \\
\hline \multicolumn{4}{|l|}{$\begin{array}{l}\text { Tobacco } \\
\text { exposure }\end{array}$} \\
\hline Tobacco use & 15.67 & 16.34 & 16.44 \\
\hline $\begin{array}{l}\text { No Tobacco } \\
\text { use }\end{array}$ & 19.73 & 15.00 & 17.11 \\
\hline$p$-value & 0.65 & 0.87 & 0.93 \\
\hline \multicolumn{4}{|l|}{ HIV Status } \\
\hline Positive & 7.66 & 0.07 & 2.57 \\
\hline Negative & 20.10 & 16.14 & 18.00 \\
\hline$p$-value & 0.27 & 0.01 & 0.02 \\
\hline \multicolumn{4}{|l|}{ Smear Status } \\
\hline Negative & 11.3 & 5.8 & 7.5 \\
\hline Positive & 19.9 & 15.6 & 17.7 \\
\hline$p$-value & 0.22 & 0.40 & 0.02 \\
\hline
\end{tabular}

QOL measures
Aariables (years)
Baseline
Bmear Status
Positive
score $\ddagger$
Overweight/
Ond
Ynevious
Yes

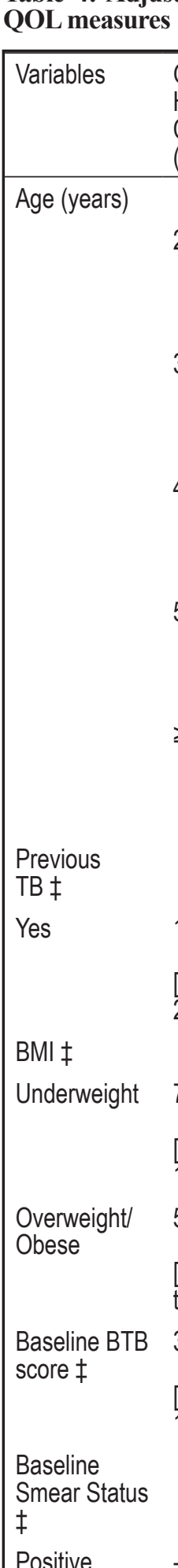

$\begin{array}{lllll}\text { Yes } & 15.72^{* *} & 13.56^{*} & 10.79 & 13.36^{*} \\ & {[4.04 \text { to }} & {[0.86 \text { to }} & {[-0.23 \text { to }} & {[2.55 \text { to }} \\ & 27.40] & 26.26] & 21.81] & 24.17]\end{array}$

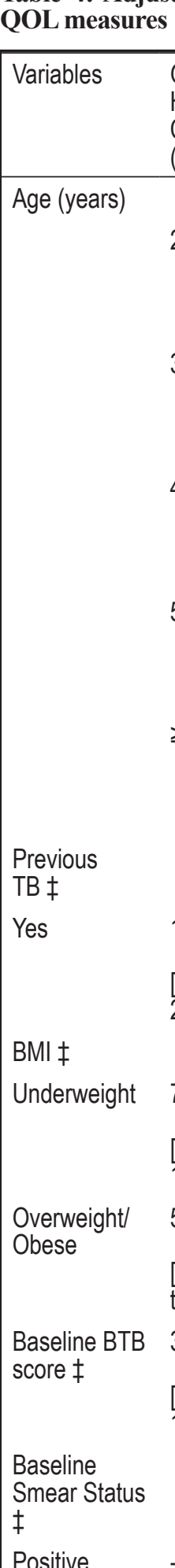

$\begin{array}{lllll}\text { Underweight } & 7.36 & 4.53 & 3.47 & 5.12\end{array}$

\begin{tabular}{|c|c|c|c|c|}
\hline & $\begin{array}{l}{[-2.26 \text { to }} \\
16.99]\end{array}$ & $\begin{array}{l}{[-5.94} \\
\text { to15.00] }\end{array}$ & $\begin{array}{l}{[-5.62} \\
\text { to12.56] }\end{array}$ & $\begin{array}{l}{[-3.79} \\
\text { to } 14.04]\end{array}$ \\
\hline \multirow{2}{*}{$\begin{array}{l}\text { Overweight/ } \\
\text { Obese }\end{array}$} & 5.30 & -0.86 & \multirow{2}{*}{$\begin{array}{l}1.06 \\
{[-17.14} \\
\text { to19.25] }\end{array}$} & 1.83 \\
\hline & $\begin{array}{l}{[-13.98} \\
\text { to24.57] }\end{array}$ & $\begin{array}{l}{[-21.83 \text { to }} \\
20.10]\end{array}$ & & $\begin{array}{l}{[-16.02 \text { to }} \\
19.68]\end{array}$ \\
\hline \multirow{2}{*}{$\begin{array}{l}\text { Baseline BTB } \\
\text { score } \ddagger\end{array}$} & 3.618 & $13.49^{* *}$ & $13.44^{* *}$ & $12.41^{* *}$ \\
\hline & $\begin{array}{l}{[-6.82 \text { to }} \\
14.06]\end{array}$ & $\begin{array}{l}\text { [3.74 to } \\
24.09]\end{array}$ & $\begin{array}{l}{[3.58 \text { to }} \\
23.29]\end{array}$ & $\begin{array}{l}{[3.28 \text { to }} \\
19.05]\end{array}$ \\
\hline
\end{tabular}

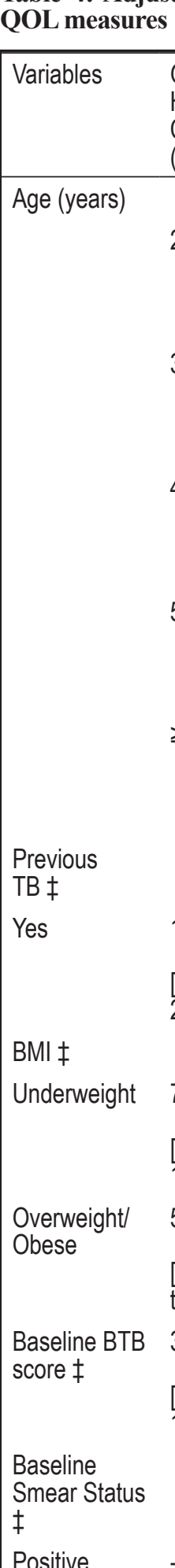

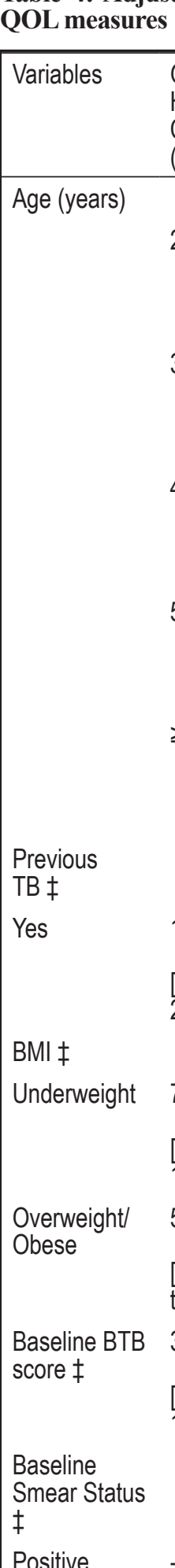

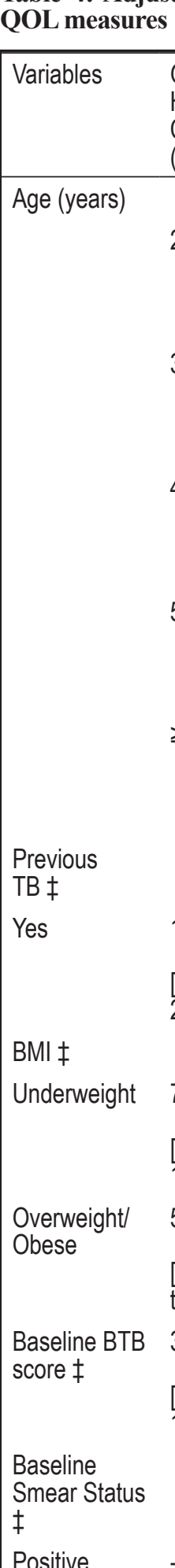

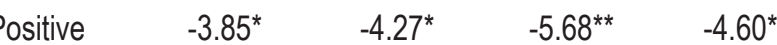

$\begin{array}{llll}{[-7.64 \text { to }} & {[-8.39 \text { to }} & {[-9.26 \text { to- }} & {[-8.11 \text { to }} \\ -0.07] & -0.15] & 2.11] & -1.09]\end{array}$

Tobacco

use $\ddagger$

$\begin{array}{llllc}\text { Yes } & 5.98 & -4.86 & 2.120 & 1.10 \\ & & & & \\ & {[-9.35} & {[-21.53} & {[-12.27 \text { to }} & {[-13.09} \\ & \text { to21.30] } & \text { to11.81] } & 16.66] & \text { to15.29] }\end{array}$

$\mathrm{p}<0.05,{ }^{* *} \mathrm{p}<0.01,{ }^{* * *} \mathrm{p}<0.001$

†Categories eliminated by backward multiple regression analysis: Age $=<20$ years; no previous history of TB; BTB score $\geq 6$, Smear negative TB, normal BMI; No tobacco use; negative HIV status; Duration of symptoms $\leq 1$ month. 
Factors associated with greatest change in HRQoL scores (MCID)

We compared the differences in scores at recruitment (before initiating treatment) and at the end of intensive phase of treatment across different demographic and clinical parameters to determine factors that accounted for greatest improvement in the HRQoL scores, (Table 3). Participants with previous history of $\mathrm{TB}$ were associated with positive change in scores in the two Health components and overall HRQoL scores, $(p=0.001$ respectively). Similarly, the duration of symptoms of less than four weeks at recruitment (before initiating treatment) was associated the largest changes in physical and mental health and overall HRQoL scores, compared with those with longer symptom duration, $(p=0.03)$. Smear positive status at recruitment was associated with significant change in the overall score compared with smear negative. Age, sex, ethnicity, baseline BMI, smoking and HIV were not associated with notable or significant changes in HRQoL scores, $(p>0.05)$, Table 3. The TB/ HIV co-infected patients were noted to have lower scores in domain and overall scores compared with PTB patients alone ( $\mathrm{p}=0.01$ and 0.02 respectively). Table 3 .

\section{$T B$ severity score and HRQoL}

The relationship between TB severity using the Bandim TB score and HRQoL was noted to show both a linear and quadratic relationship (Figure 2). Overall HRQoL score was influenced by the BTB score. As the BTB score increased, the mean value of the HRQoL domains and overall score increased up to score of 6 following which there was a decline.

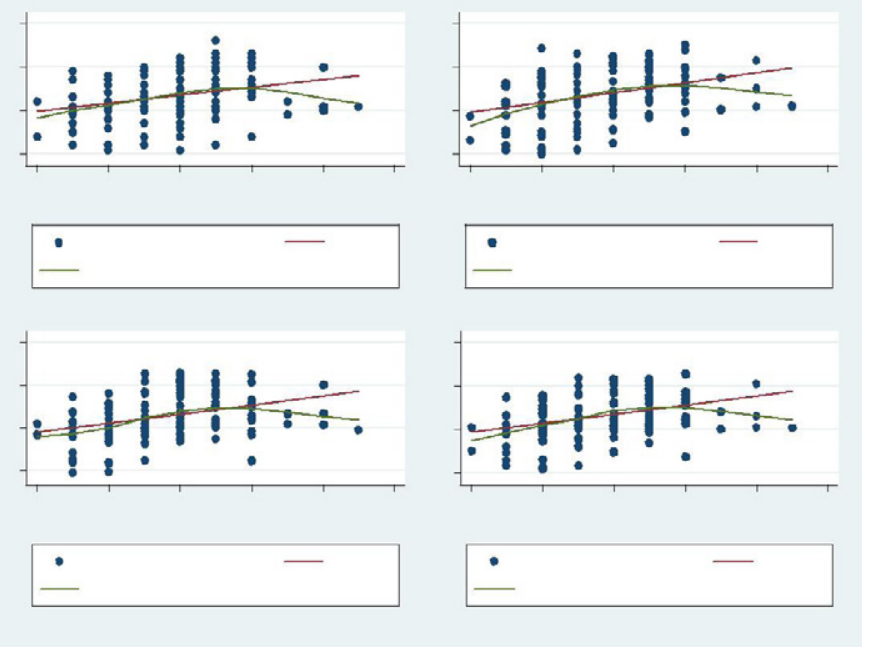

Figure 2: Scatter plots of Bandim TB severity score against QOL scores with smoothed plots

\section{Predictors of greatest change in HRQoL scores}

Using the MCID score, Table 4 shows the predictors of significant change in the physical and mental health components and the overall scores. Previous history of TB was a strong predictor of significant change in the physical health component and overall scores, $(p<0.05)$. HIV positive status was associated with a marked reduction in mental health and overall HRQoL scores $(\mathrm{p}<0.05)$. The TB severity score, as measured by Bandim TB Score was a significant predictor of physical and mental health change and overall scores, baseline Smear status was a significant predictor of all the HRQoL domains with greatest impact on the mental health component, Table IV.

Table 5: Association between socio-demographic variables, QOL and treatment default at end of 2 months

$\begin{array}{llll}\text { Defaulters } & \begin{array}{l}\text { Intensive } \\ \text { phase } \\ \text { completed }\end{array}(\%) \quad \text { p-value } & \begin{array}{l}\text { Odds } \\ \text { ratio }\end{array} \\ n(\%) & & \\ & & \\ \text { Bivariate analysis } & & \begin{array}{l}\text { Logistic predictors of non } \\ \text { defaulters at 2months }\end{array}\end{array}$

\begin{tabular}{lllllll}
\hline $\begin{array}{l}\text { Age } \\
\text { (years) }\end{array}$ & & & & & & \\
$\begin{array}{l}\text { less than } \\
30\end{array}$ & $11(64.7 \%)$ & $42(31.5 \%)$ & 0.04 & 0.3 & $0.08-$ & 0.9 \\
30 and & $6(35.3 \%)$ & $91(68.5 \%)$ & & 1 & & \\
above & & & & & & \\
Sex & & & & & & \\
M & $7(41.2 \%)$ & $72(54.1 \%)$ & 0.08 & 2.1 & $0.9-3.5$ & 0.08 \\
F & $10(58.8 \%)$ & $61(45.9 \%)$ & & 1 & & \\
Previous & & & & & & \\
TB & & & & & & \\
Yes & $5(29.1 \%)$ & $25(18.8 \%)$ & 0.07 & 0.5 & $0.1-1.2$ & 0.9 \\
No & $12(70.9 \%)$ & $108(81.25)$ & & 1 & &
\end{tabular}

Smoking

History

$\begin{array}{lllllll}\text { Yes } & 3(17.6 \%) & 12(9 \%) & 0.08 & 3.4 & 0.9-4.7 & 0.07 \\ \text { No } & 14(82.4 \%) & 119(91 \%) & & 1 & & \\ \text { TB severity } & & & & & \end{array}$

class

\begin{tabular}{lllllll} 
I & $10(58.8 \%)$ & $99(74.4 \%)$ & 0.06 & 1.9 & $0.9-3.5$ & 0.06 \\
II & $4(23.5 \%)$ & $21(15.7 \%)$ & & 1.2 & $0.3-2.4$ & \\
III & $3(17.6 \%)$ & $13(9.8 \%)$ & 1 & & \\
$\begin{array}{l}\text { Duration } \\
\text { of illness } \\
\text { (months) }\end{array}$ & & & & & & \\
0-3 & $7(41.2 \%)$ & $57(42 \%)$ & 0.9 & 2.1 & $0.9-3.3$ & 0.09 \\
3-6 & $6(35 \%)$ & $27(20.3 \%)$ & & 1.9 & $0.07-$ & \\
$\begin{array}{l}\text { 6 and } \\
\text { above }\end{array}$ & $5(27 \%)$ & $49(36.8 \%)$ & & 1 & & \\
$\begin{array}{l}\text { Physical } \\
\text { functioning } \\
\text { domain }\end{array}$ & & & & & & \\
$\begin{array}{l}\text { Less than } \\
\text { 45 }\end{array}$ & $2(11.6 \%)$ & $73(54.9 \%)$ & 0.03 & 5.3 & $1.11-$ & 0.01 \\
$\begin{array}{l}\text { More than } \\
\text { 45 }\end{array}$ & $15(88.4 \%)$ & $60(45.1 \%)$ & & 1 & & \\
\hline
\end{tabular}

\section{Effect of HRQoL on default rates}

Table 5 shows bi-variate and multiple regression analyses of factors associated with default among the cohorts. Age and baseline score of physical functioning domain were significantly associated with default. However, gender, past medical history of TB, previous tobacco use, TB severity class and duration of illness before recruitment were not significantly associated with treatment default by the end 
of two months $(\mathrm{p}<0.05)$. Multiple regression analysis of predictors of default identified PF score of more than 45 as having greater chances of defaulting treatment $(\mathrm{OR}=5.3$; 95\%CI: 2.11-9.05, $\mathrm{p}=0.01)$. Defaulters also tended to be younger (median age, IR 29.3(10.4) years) compared with those who completed intensive phase treatment (median age $36.9(16.7)$ years), $\mathrm{p}=0.04$

\section{Discussion}

This cross-sectional study among a sample of both smear positive and smear negative TB patients in Nigeria provided insights into their HRQoL scores and how these vary with the treatment (end of intensive phase). We noted that there were significant changes in the total HRQoL scores in all domains and the two components, except the emotional well-being domain. Defaulters had significantly higher score on physical functioning compared with those that completed the intensive phase. HIV negative status, mild TB as measured by Bandim TB score, sputum smear status and previous history of TB were predictors of largest increase/ greatest improvement in HRQoL scores at the end of two months of treatment.

Though no comparisons with healthy individuals were done before commencing therapy, it has been shown that TB patients have lower scores on most domains tested, compared with healthy individuals ${ }^{5-7,13,18,19}$. Component summary scores obtained in those studies among TB patients were higher than what we reported, but our findings were similar to report from South Africa ${ }^{20}$. The scores in both our study and the South African study reported lower than the normbased scoring point considered to be indicative of impaired function within that health domain or dimension ${ }^{15}$. This is probably reflective of the similarities in socio-economic parameters. We observed a higher mean score on the mental health component compared with the physical health component. This is consistent with earliest observations by Chamla ${ }^{18}$ where patients also had lower score on physical health component. Following two completed months of anti-TB medications, in addition to sputum conversion in the majority of the patients, chemotherapy also had a positive effect on HRQoL. Patients had significant improvement on all domains, the physical and mental components and over all scores, except emotional well-being domain. The mean change in physical component summary score at the end of two months was larger than what was observed in the mental component summary score. It appeared that though physical health seemed to be more affected prior to treatment, it improved by the end of intensive phase of treatment. This trend has been observed before ${ }^{18,19,-21}$. It may therefore mean that the emotional problems and anxiety mainly due to stigma, fear of rejection and sometimes loss of income that these individuals experience does not abate but could become heightened ${ }^{7-10}$.

As shown in this study, defaulters had better score on physical functioning. Patients with higher score on physical functioning had a five-fold chance of defaulting. Better perception of their physical health, howbeit wrongly and reduced limitation of physical functioning due to the disease, may make the individual doubtful of the correctness of their diagnosis. These perceptions of the patients, the initial rapid resolution of symptoms and side effects of medications may encourage default to treatment. Despite the small number, it may be right to state that individuals with higher score on physical functioning domain may have issues complying with treatment. Since the noted group are somewhat still agile, and do not consider themselves as that sick, they may find it more appropriate to embark on income fetching ventures rather than daily hospital visits for medications. Such individuals should be recognized and should receive personalized counsel. Within our context, where the pharmacy-driven programme ${ }^{22}$ is not practiced, alternatives like Video observation of therapy may also be considered ${ }^{23,24}$.

In a multivariable analysis, history of previous TB, baseline severity score up to 6 , negative smear status and HIV negative status were significantly positively correlated with increase in QoL score at the end of two months. The expectation would have been that previously treated patients will report poorer HRQoL due to complications such as lung fibrosis ${ }^{25}$. However, it turned out not to be so. Could this be a case of passing through the same road twice and now better accustomed to it, or whether it was due to development of coping strategies or the quality and satisfaction of care previously received for TB? It is difficult to say. However, since majority of our study participants have only been treated once, and they had mild disease, the usual post tuberculosis sequel like fibrosis may be minimal with limited or no functional impairment compared with what those with multiple treatments and drug resistance TB may experience ${ }^{26}$. This may partly explain why the greatest improvement was recorded in the physical component summary. Conversely, HIV positive co-infected TB patients had a significant lower change on the mental component summary and overall scores compared with those who were HIV negative.

Issues concerning HRQoLin TB/HIV co-infected individuals have not been straight forward due to the confounding impact of other variables like use of antiretroviral drugs, and concurrent opportunistic conditions ${ }^{27}$. In consonance with our findings, report from a South African study, with 4900 participants who had TB, of whom $60 \%$ were HIV co-infected, found that HIV infection was associated with a significantly lower health status ${ }^{20}$.

Mild disease was positively correlated to greatest improvement in the two components and overall scores, and smears positive status was significantly negatively correlated with those same parameters. These two predictors had the lowest $\mathrm{p}$ values, indicating their relative strength in predicting marked improvement in the HRQoL. A less severe disease is likely to have minimal structural damage and functional impairment ${ }^{26}$. The absence of functional impairment may ameliorate any psychological issues in mild/moderate disease. Consistent with our finding, Dhingra et $\mathrm{al}^{28}$ and Sule et $\mathrm{al}^{29}$ demonstrated a higher HRQoL scores among smear negative TB patients compared with smear positive ones. It has also been shown that the presence and load of Mycobacterium tuberculosis correlate with symptom severity ${ }^{30}$. Taken together, individuals with smear positive TB are likely to have more symptoms and this could affect the degree of improvement in the HRQoL with treatment as shown in our study.

This study is limited in that comparisons with healthy individuals and an end of treatment assessment of HRQoL at 6 months were not done. Although, there were improvements in 2 and 6 months scores following treatment, many patients still have residual impairment as reported by Aggarwal et $\mathrm{al}^{31}$. Moreover, other reports had shown no difference in the two and six months scores ${ }^{32,33}$. However, report by Bauer et al reported that most impairments in HRQoL are most pronounced during the weeks after diagnosis and treatment 
initiation, but is no longer evident after two months ${ }^{6}$. We did not evaluate for the variations that could have been due to drug resistant strains as well. Despite these limitations, we have shown that HRQoL scores improve significantly, except emotional well-being, after two months of treatment. Even though physical component summary score seems to be worse before treatment, it appeared to greatly appreciate by the end of intensive phase. Patients with better physical functioning had five-fold chance of defaulting. This interaction between default and HRQoL, to our knowledge, has not been previously recognized before in most HRQoL studies in TB. The impact of anti-TB medications on the HRQoL scores was obvious. Nevertheless, HIV-positive status, severe disease and smear positivity were associated with minimal improvement in HRQoL scores by the end of intensive phase.

\section{Conclusion}

All aspects of quality of life is affected but the emotional domain is the least affected in patients on treatment for tuberculosis. Younger patients with no physical impairment are more likely to default treatment. HRQoL assessment could form a veritable tool for patients' evaluation and outcome measure in DOTS. We hereby recommend that attempts should be made to address concerns of emotional problems and anxiety mainly due to stigma and fear of rejection, during care giving sessions especially in DOTS settings. We also recommend that individuals with high physical function score must be recognized and should receive personalized counsel at recruitment to encourage adherence to therapy. Pharmacy based programmes are also an area for further study within our context. A shorter form of the HRQoL questionnaires may need to be introduced into DOTS clinics and scores that are highly discriminant of defaulters obtained to ascertain patients who need closer monitoring. This may be a novel way of dealing with the issue of default in TB treatment.

\section{Acknowledgements}

We acknowledge the support of staff and patients of TB clinics in OAUTHC, Ile Ife, Enuwa and Moro during the conduct of this study.

\section{References}

1. Guyatt GH, Feeny DH, Patrich DL. Measuring health-related quality of life. Ann Intern Med 1993, 118 (8):622-629. doi: 10.7326/00034819-118-8-199304150-00009

2. Sherbourne CD, Sturm R, Wells KB. What outcomes matter to patients. J Gen Intern Med 1999; 14 (6):357-363. doi: 10.1046/j.15251497.1999.00354.x.

3. Global tuberculosis report 2017. Geneva: World Health Organization; 2017. Available at ww.who.int/tb/publications/global report.

4. Marca CA, Marra F, Cox VC, Palepu A, Fitzgerald JM. Factors influencing quality of life in patients with active tuberculosis. Health Qual Life Outcome 2004; 2:58. doi: 10.1186/1477-7525-2-58.

5. Guo N, Marra CA, Marra F, Moadebi S, Elwood RK, Fitzgerald JM. Health state utilities in latent and active tuberculosis. Value Health 2008, 11 (7):1154-1161. doi: 10.1111/j.1524-4733.2008.00355.x.

6. Marra CA, Marra F, Colley L, Moadebi S, Elwood RK, Fitzgerald JM. Health related quality of life trajectories among adults with tuberculosis: differences between latent and active infection. Chest 2008; 133 (3):396-403. doi:10.1378/chest.07-1494

7. Macq J, Solis A, Martinez G, Martiny P, Dujardin B. An exploration of the social stigma of tuberculosis in five municipios of Nicaragua to reflect on local interventions. Health Pol 2005; 74 (2):205-217. doi: https://doi.org/10.1016/j.healthpolicy.2005.01.003.

8. Rajeswari R, Muniyandi M, Balasubramanian R, Narayanan PR. Perceptions of tuberculosis patients about their physical, mental and social well-being: A field report from South India. Soc Sci Med 2005; 60 (8):1845-1853. https://doi.org/10.1016/j.socscimed.2004.08.024.

9. Long NH, Johansson E, Diwan VK, Winkvist A. Fear and social isolation as consequences of tuberculosis in Vietnam: A gender analysis. Health Policy 2001; 58 (1):69-81. doi:10.1016/S0168-8510(01)001439.

10. Kelly P. Isolation and stigma: the experience of patients with active tuberculosis. J Community Health Nurs 1999; 16 (4):233-241. DOI:10.1207/S15327655JCHN1604_3

11. National Tuberculosis and Leprosy Control Programme: Workers Manual. Federal Ministry of Health of Nigeria. Department of Public Health, Abuja; 5th ed. 2010; pp 10-19, Print.

12. von Elm E, Altman DG, Egger M, Pocock SJ, Gøtzsche PC, Vandenbroucke JP et al. Strengthening the Reporting of Observational Studies in Epidemiology (STROBE) statement: Guidelines for reporting observational studies. BMJ.2007;335(7624):806.8doi:10.1136/ bmj.39335.541782.AD

13. Guo N, Marra F, Marra CA: Measuring health related quality of life in tuberculosis a systematic review. Health Qual Life Outcome 2009; 7:14. https://doi.org/10.1186/1477-7525-7-14.

14. Kruijshaar ME, Lipman M, Essink-Bot ML, Lozewicz S, Creer D, Dart $\mathrm{S}$ et al. Health status of UK patients with active tuberculosis. Int J Tubers Lung Dis 2010, 14: 296-302. PMID: 20132620.

15. Ware JE, Kosinski M, Bjorner JB, Turner BDM, Maruish ME. User's manual for the SF-36 v2 health survey. 2nd ed. Lincoln, RI: Quality Metric Incorporated; 2007.

16. Mbada CE, Adeogun GA, Ogunlana MO, Adedoyin RA, Akinsulore A, Awotidebe TO et al. Translation, cross-cultural adaptation and psychometric evaluation of Yoruba version of the short-form 36 health survey. Health Qual Life Outcomes. 2015 14; 13:141. DOI: 10.1186/ s12955-015-0337-y.

17. Wejse C, Gustafson P, Nielsen J, Gomes VF, Aaby P, Andersen PL et al. TB score: Signs and symptoms from tuberculosis patients in a low-resource setting have predictive value and may be used to assess clinical course. Scand J Infect Dis 2008; 40 (2):111-20. DOI:10.1080/00365540701558698.

18. Chamla D. The assessment of patients' health-related quality of life during tuberculosis treatment in Wuhan, China. Int J Tuberc Lung Dis 2004; 8 (1):1100-1106. PMID: 15455595.

19. Wang Y, Lii J, Lu F. Measuring and assessing the quality of life of patients with pulmonary tuberculosis. Zhonghua Jie $\mathrm{He} \mathrm{He} \mathrm{Hu} \mathrm{Xi} \mathrm{Za}$ Zhi 1998; 21:720-723.

20. Louw J, Peltzer K, Naidoo P, Matseke G, Mchunu G, Tutshan B. Quality of life among tuberculosis (TB), TB retreatment and/or TB-HIV co-infected primary public health care patients in three districts in South Africa. Health Qual Life Outcomes 2012; 10: 77 DOI: 10.1186/14777525-10-77.

21. Dhingra VK, Rajpal S. Health related quality of life (HRQL)scoring (DR-12 score) in tuberculosis - additional evaluative tool under DOTS. J Commun Dis 2005; 37 (4):261-268.

22. Tannenbaum C, Tsuyuki RT. The expanding scope of pharmacists' practice: Implications for physicians. CMAJ 2013;185 (14):11228-32. DOI:10.1503/cmaj.121990.

23. Abimbola S, Ukwaja KN, Onyedum CC, Negin J, Jan S, Martiniuk ALC. Transaction costs of access to health care: Implications of the care-seeking pathways of tuberculosis patients for health system governance in Nigeria. Global Public Health 2015; 10 (9):1060-1077, DOI: $10.1080 / 17441692.2015 .1007470$.

24. Garfein RS, Collins K, Muñoz F, Moser K, Cerecer-Callu P, Raab F et al. Feasibility of tuberculosis treatment monitoring by video directly observed therapy: a binational pilot study._Int J Tuberc Lung Dis. 2015; 19:1057-64. DOI: 10.5588/ijtld.14.0923.

25. Dheda K, Booth H, Huggett JF, Johnson MA, Zumla A, Rook GA. Lung remodelling in pulmonary tuberculosis. J Infect Dis. 2005; 192 
(7): 1201-1209. https://doi.org/10.1086/444545.

26. Di Naso FC, Pereira JS, Schuh SJ, Unis G. Functional evaluation in patients with pulmonary tuberculosis sequelae. Rev Port Pneumol 2011; 17:216-21 https://doi.org/10.1016/j.rppnen.2011.06.005.

27. Brown J, Capocci S, Smith C, Morris S, Abubakar I, Lipman M. Health status and quality of life in tuberculosis. Int J Infect Dis 2015;32: 68-75. DOI: 10.1016/j.ijid.2014.12.045.

28. Dhingra VK, Rajpa S. Health Related Quality of Life (HRQL) Scoring in Tuberculosis. Ind J Tub 2003; 50:99

29. Sule AG, Odeigah LO, Alabi KM, Issa BA, Shittu RO, Joseph AI et al. Quality of Life of Patients with Tuberculosis in a Nigerian Teaching Hospital. TJFMPC 2014; 8 (2):25-33. DOI10.5455/tjfmpc.46982.

30. Hales CM, Heilig CM, Chaisson R, Leung CC, Chang KC, Goldberg SV et al. The Association between symptoms and microbiologically defined response to tuberculosis treatment. Annals of the Ann Am Thorac Soc 2013;10:18-25. https://doi.org/10.1513/ AnnalsATS.201207-038OC.
31. Aggarwal A N, Gupta D, Janmeja A K. Jindal SK. Assessment of health-related quality of life in patients with pulmonary tuberculosis under programme conditions. Int J Tuberc Lung Dis. 2013; 17 (7):94753. DOI: 0.5588/ijtld.12.0299.

32. Mamani M, Majzoobi MM, Ghahfarokhi SM, Esna-Ashari F, Keramat F. Assessment of Health-related Quality of Life among Patients with Tuberculosis in Hamadan, Western Iran. Oman Med J 2014;29 (2):102- 05. DOI: 10.5001/omj.2014.25.

33. Atif M, Sulaiman AS, Shafie AA, Asif M, Sarfraz MK, Low HC et al. Impact of tuberculosis treatment on health-related quality of life of pulmonary tuberculosis patients: a follow-up study. Health Qual Life Outcomes 2014; 12:19-23. https://doi.org/10.1186/1477-7525-12-19. 